Elisabete Lamy Luz ${ }^{1}$ Marta Lima Basto ${ }^{1}$

\footnotetext{
${ }^{1}$ Departamento de Ciências da Saúde, Universidade Católica Portuguesa. Edifício da Biblioteca João Paulo II/5ㅇ Piso, Palma de Cima. 1649-023 Lisboa Portugal.

luzelisabete10@gmail.com
}

\section{The opinion of patients with COPD: the process of becoming chronically sick}

\author{
Vozes das pessoas com DPOC: \\ o processo de tornar-se doente crónico
}

\begin{abstract}
Many earlier studies have contributed to a general understanding of the symptoms and signs of chronic obstructive pulmonary disease (COPD), yet very little is known about the transition from a healthy to a chronically sick individual. The scope of this study was to understand how people live with their chronic illness, using Grounded Theory ${ }^{1}$. Twenty-two participants with COPD were interviewed. Findings revealed "the basic social process" of becoming sick with COPD: The significance of living with COPD; Stages of becoming a sick individual; Strategies for management of the process used by participants. The conclusion reached is that understanding the process of "becoming sick" from the person's perspective assists nurses to develop personalized interventions with individuals suffering from COPD, focussing on the subject of care.
\end{abstract}

Key words Nursing, Community nursing, COPD patient, Public health, Chronic disease, Transition
Resumo Os vários estudos realizados no âmbito da DPOC têm focalizado o seu objeto de estudo na compreensão dos sinais e sintomas da doença, no entanto pouco se conhece sobre a transição de saudável a doente. Então como é que as pessoas com DPOC vivem o processo de transição de saudável a doente? O método utilizado foi a Teoria Fundamentada. Realizámos 22 entrevistas abertas a pessoas com DPOC. O Processo Social Básico (PSB), encontrado neste estudo é "tornar-se doente" expressa o conceito central do estudo e procura dar resposta à questão de investigação: O PSB é composto pelos seguintes códigos temáticos: O significado de viver com a DPOC; Estádios do processo de tornar-se doente; Estratégias de gestão do processo. Consideramos que o conhecimento do processo de "tornar-se doente", ajuda os enfermeiros a desenvolver intervenções individualizadas às pessoas com DPOC, focalizando-se no sujeito de cuidados. Palavras-chave Enfermagem, Enfermagem comunitária, Pessoa com DPOC, Saúde Pública, Doença crónica, Transição 


\section{Introduction}

Chronic obstructive pulmonary disease (COPD) is the fifth leading cause of death worldwide and is a major personal and Public Health problem. The prevalence and incidence of COPD continues to increase not only in Portugal but also worldwide.

In Portugal, COPD is the seventh cause of death, increasing 2\% over 5 years (1998-2002). Several international studies have explored patients' experiences on living with $\mathrm{COPD}^{1-15}$. All these studies add new knowledge to understand people with COPD living transitions experience. Still, there is a need to study further the lived experience of people with COPD from a nursing perspective, specifically as a way of helping people going through transitions. The research question that guided the present study was: How do persons with COPD live through the transition from wellness to illness?

\section{Background}

The main health problem of people suffering from chronic respiratory disease is dyspnoea. Dyspnoea affects all aspects of life psychological, social, and physical. Patients with breathing alternations must be seen as unique ${ }^{16}$ and at the same time, as persons in transition ${ }^{17}$, Transition from feeling healthy to feeling sick, represent a life process with complex interactions between environment and person. Transition is influenced by the social context and the person's health situation ${ }^{17,18}$. The concept of transition represents a process that involves a change in the life of a person. Understanding the transition process allows healthcare professionals to help their patients to change; nurses can plan activities according to their knowledge of the transition ${ }^{19}$. Doing so will not only enable nurses to better help patients deal successfully with problems they may encounter as the disease progresses but also will help nurses stimulate their patients' potential.

Nursing is defined "as being concerned with the processes and experiences of human beings undergoing transitions where health and perceived well-being is the outcome" ${ }^{17}$ as well as "the art and science of facilitating the transition of populations' health and well- being ${ }^{20}$. Understanding and identifying life transitions that people experience enables nurses to develop innovative therapeutic interventions based squarely on what people are living and feeling. This understanding also gives nurses direction to help pa- tients self-manage during the transition, thereby facilitating the passage through life.

\section{Purpose}

The aim of the study was to understand the transitional experiences of persons with COPD in order to contribute to a higher quality of nursing care.

\section{Methodology}

\section{Design and sample}

The research question called for a qualitative approach, grounded theory being appropriate to understand psycho-social processes ${ }^{21}$. Through a qualitative approach, interviews were held with a convenience sample of 22 participants, 17 were men and five women with chronic obstructive pulmonary disease with confirmed diagnosis at least two years before the study, regardless of level, as defined by the Global Initiative for Chronic Obstructive Lung Disease ${ }^{22}$. The youngest was 26 years old and the oldest 72 years old. This way a theoretical sampling was formed by 22 participants, all of them were informed about the study and accepted to participate. One participant refused to participate after the interview.

\section{Setting}

We contacted two hospitals in Lisbon, Portugal, with outpatient facilities for persons with respiratory diseases and RESPIRA, a Portuguese association of persons with COPD and other respiratory diseases formed in 2007, all of them agreeing to take part in our study. Professionals from one hospital indicated four patients in home care that could participate in our study; the researcher visited them at home with the hospital home team and did two interviews. Other hospital referred 11 outpatients and we contacted them in the hospital. The RESPIRA President referred 15 potential participants that were contacted by phone. From these 15 we only contacted 11 participants, and one was on holiday so we did 10 interviews in the participant's home.

\section{Data collection}

Data were collected over 6 months, between June 30, 2008, and December 7, 2008. The author conducted face to face interviews at different lo- 
cations, which were chosen by the participants according to their availability. The length of the interviews was between 15 minutes and one hour and 40 minutes. A semi structured interview guide was used throughout the interview. The interview questions focused on the effect of COPD on everyday activities and relationships, the emotional feelings associated with the disease and the participants' experiences with dyspnoea. However interviews were conducted in a very flexible manner to allow participants to share topics, perspectives, and meanings that were important to them, and to allow the interviewer to explore all issues raised throughout the interview process. Open-ended questions were asked to encourage participants to describe their subjective experiences without being led by the interviewer, and to obtain as much data as possible. After the interviews, the tapes were transcribed by the author with the participants' permission. Interview tapes and transcripts were not identified in order to ensure participant confidentiality.

\section{Data analysis}

Transcripts from the personal interviews served as the raw data in this study. Data were analyzed during data collection, and were analyzed line by line to form categories, search for and identify processes, meanings, actions, change, and consequences ${ }^{21}$. Using theoretical coding, the relationship between the categories and concepts were identified, and the focused codes integrated and organized into at the Basic Social Process that emerged: "Becoming a sick person". To ensure the Basic Social Process had fit, relevance, and modifiability, trustworthiness of the data was sought using the criteria of credibility and reliability. Reliability was verified through debriefing with two colleagues, good interview techniques, coherence, and referential adequacy. These colleagues were not involved in the study. Credibility was assured by a referential adequacy of the data obtained by gathering rich, in-depth information from interviews, field notes, and memos, and by transcribing verbatim and coding line by line using the participant's words as much as possible. After that, our colleagues analysed the data. There was $85 \%$ of consensus with the findings. The researcher decided to do some modifications based on colleagues evaluation.

\section{Ethical considerations}

Both hospitals Institutional Review Boards approved this study. No patient identifying information is reported here, and all names were coded into number designators for the study. Participants knew their own number.

\section{Findings}

The participants gave descriptions about how they become sick and how the illness influenced every aspect of their daily activities. We used the transition concept to understand the process of becoming a sick person. This Basic Social Process expresses the Central Concept of the study and answers to the research question: How do persons with COPD live through the transition from wellness to illness? Our findings revealed a process that persons with COPD passed through during his/her life.

This Basic Social process is compounded by three theoretical codes:

. Meanings of living with COPD;

. Stages of becoming a sick person;

. Management strategies used by participants (Figure 1).

\section{Meanings of living with COPD}

In order to understand how a person becomes sick, we must understand the meanings of their bodily experiences and social context as these meanings are constructed in a dialectic relation to their biographies ${ }^{1 .}$. They expressed how COPD affected their lives, acknowledging the progressive nature of the disease. These interpretations mediated their experience ${ }^{21}$.

During this transitional experience, people with COPD may find that their limitations may also lead to some newly found benefits ${ }^{23}$. These benefits were highlighted by one participant:

... [Having COPD afforded me] the 'privilege' of not climbing the stairs, as there was no lift. So a doctor, met me at the beginning of the workday downstairs at the entrance [...] For me this was an advantage [...] it was more profitable to talk to the doctor at the beginning [of the day] than at the end of his consultation [day], since it was more likely he [the doctor] would buy something that I was going to offer him [as part of his role as a laboratory salesman]. (E5) 


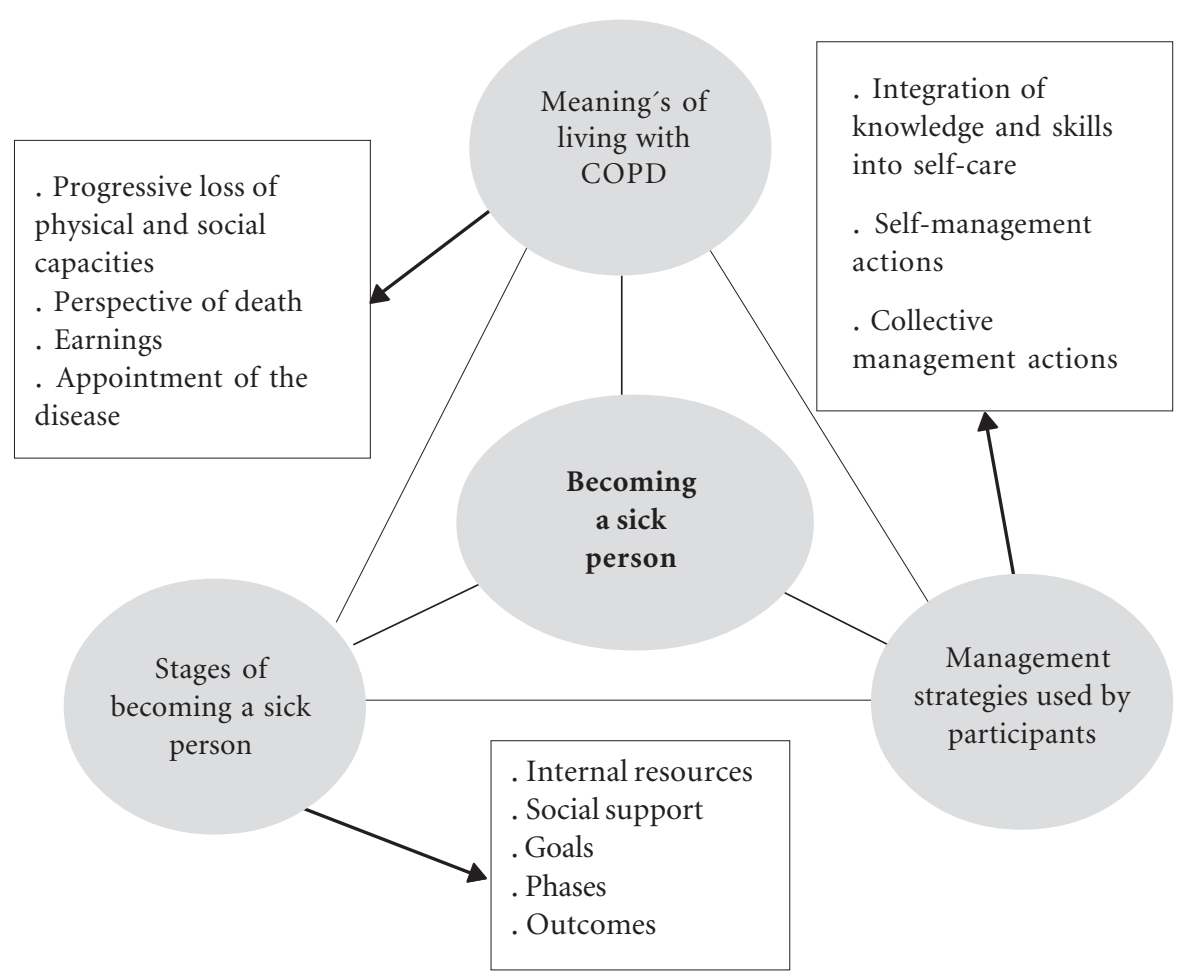

Figure 1. Diagram of the study findings.

Another important aspect, which can affect the meaning of the experience of being a sick person is the ability of people with COPD to know the name of the disease and the testes that contribute to the diagnosis of the disease:

[...] I've been dragging for 6 or 8 months, and it was becoming increasingly worse. And then when I decided to get treatment, that was when I was told I had chronic obstructive pulmonary disease. (Silence). (E19)

The way each of us lives depends in part on how we approach life, even when confronted with a chronic disease such as COPD. Some participants experienced changes in their quality of life. Interpretations of experience depend on how people have been living their lives. We consider that understanding the meaning of lived experience of being a COPD patient gives nurses information that helps them to understand individuality and integrity of each person and when nurses have this comprehension they can help people to follow their path in the process of becoming a sick person.

\section{Stages of becoming a sick person}

COPD is a progressive disease that worsens with time. Becoming sick can be considered a learning process, during which a person acquires knowledge and experience, becoming an expert about his/her disease. The idea that this process depends largely on internal skills that compel persons to deal with their disease at different levels, emerges from the data analysis. However, this process will only occur if the person is aware that he/she really needs to change, as reflected in the comments of comments of one participant:

[...] each person must find their way [on how] to live with these things. [Chronic respiratory diseases like COPD] are [...] very much like any [other] disease: [It] stirs up a lot in us and not what others say is what we get [...] [Getting through the disease] is an inner process of acceptance and moving forward. [...] [It requires] $a$ lot of fortitude and a lot of decisions [...]. (E8)

It is important for nurses to understand that suffering may be the driving force that triggers this process, it is also equally important for nurses 
to understand that this process help patients with COPD to grow as a person and to develop coping skills.

Findings suggest that environment of persons with COPD can influence person's experience process of feeling sick, one of the participants said:

[...] the stagnant air keeps me from going out [...]. (E1)

Other says: I seldom go to parties or gatherings. I don't like to drive out in restaurants that are filled with smoke [...]. (E8)

Patients integrate environmental control behaviours in their lives ${ }^{11}$.

People with COPD commit themselves to achieving their goals during the process. Objectives are goals that people reach out for when they start this process. The data collected also indicated that the objectives of a person with COPD change in accordance with the experiences he/she acquires. One participant reflected this:

Since the TAC [computed axial tomography], [...] [the doctor] [...] clarified any doubts, [she] was very direct, I had to think 'what do you want for your life' and then [I] had to decide. (E8)

For people with COPD, the illness begins to reflect on their identity, on their awareness of self $\mathrm{f}^{17,19,24}$. This statement reflects that it is important to have self-determination to do things and this influences the process of becoming a sick person.

We identified two phases in this process: Crisis and Chronic states. Participants referred that they were different but with three common elements: symptoms, feelings and constrains. These elements have been identified previously in other studies.

During crisis participants said that dyspnoea was the main principle symptom, anxiety and panic were the main principal feelings. It was interesting that all the 19 participants referred some constrains in this phase such as: they didn't know they were sick, they went to hospital over and over again with dyspnoea and after that they went home with medication, but without a diagnosis and they didn't care about it, they didn't pay attention. In the chronic phase they referred physical limitations as principal complains and they were sad and angry with themselves.

During the process of becoming a sick person, persons diagnosed as suffering from COPD had obtained experience and knowledge and these are outcomes of the process. Patients with COPD chose suitable disease self-management behaviors, based on experience, wisdom and professional guidance ${ }^{1}$.This results will enable nurses to select strategies that will enhance patient care and their management and promote the best quality of life possible within the limits set by individual capabilities ${ }^{25}$.

\section{Management strategies used by participants}

The integration of knowledge and skills into self-care were important strategies for persons with COPD. The interviews revealed that the ability to solve problems was developed over time. On participant stated:

[...] solve the [congestion] problems [with] Finatux [carbocisteine], [...] and avoid the Augmentin-Duo; clean everything, there is no infection that can withstand anything [...]. (E6)

He had integrated information he received from healthcare providers and incorporated it into his life. In the context of solving problems related to one's health, another participant claimed that he was able to self-assess his health.

I see how I get if I'm more relieved or attacked, and I take [medication] according to my symptoms. We must do according to our experiences, as our own machinery [dictates] and [as according to what] we need. (E20)

Thus, some COPD patients are able to solve their health problems by assessing their situation and responding based on their experience. Knowledge of their disease and how to treat it is acquired over time. Another way patients with COPD can integrate knowledge about their disease into their disease-management skills is through self-care. Self-care is the practice of activities that an individual adheres to for his/her own benefit and to maintain life, health, and wellness ${ }^{26}$.

We noted that a person with COPD himself could create conditions to manage his/her disease and live with it. One participant stated:

So there must be conditions [...] [I'm] prohibited from having the flu. [I] cannot let emphysema or COPD develop, or at least symptoms like a temperature, quench temperature (Laughs) [...] Be careful not to catch cold, [...] [I] do not take anything for the disease so it does not evolve. (E11)

The participants viewed the self-management of therapy as actions that allow them to control symptoms and the disease itself, leading to stabilisation. This view was also reported by some authors $^{1,10}$.One participant stated:

[...] do drug therapy, I use ... a product that I inhale every morning.... I do well; I feel that [this product] has the power to dilate my [pulmonary] veins. (E11)

Another participant also mentioned using non-invasive ventilation to control symptoms: 
Now I am using bip bap [mechanical ventilator ]. [I feel] a little [better] a bit, but I think it is not well at all [...] I will do the sleep study now in September, and then they will set the bip bap parameters [...]. (E13)

Regarding the importance of managing one's emotions, the participants reported that stress interfered with their breathing:

[...] [I] can sometimes be a bit more stressed ... Or may not be [...]. When you're talking to sponsors, tension is very different from what I now have [...] at home, [where I can] talk [...] freely [...] I feel that the oxygen helps me in the sense that it helps me to relax. (E4)

Other studies also observed that stress and changes in patients' daily activities affected the breathing of patients with COPD ${ }^{5,7,8,10,11,27-29}$. COPD patient's advocate associations like RESPIRA to promote the strategy of encouraging persons with COPD to take accountability for their own health. In Portugal, the National Health Service (NHS) has taken on the role of promoting accountability through health policies and programmes such as the Prevention of Chronic Obstructive Pulmonary Disease Programme. The participants of the present study voiced frustration at such programmes and noted that patientadvocate associations need to play a more empowering role in promoting programmes applicable to the COPD context. Indeed, leadership is essential in order for such associations to fulfil their mission, as one of the participants noted:

[...] we [people with COPD] are 500 thousand, yet no one gets together, nobody is organised! We are many here, but we walk in the wind [...] It makes little sense. (E4)

Participants clearly emphasised the importance of integrating knowledge and skills into selfcare. Expertise can be defined as the skills that people acquire over the management of their new situation or environment ${ }^{24}$. The management strategies described by the study participants give information to nurses about ways that persons integrate knowledge about their experience and developed competences to self manage the process of becoming sick.

\section{Discussion}

The process of becoming sick is it a passage, a transition and it is characterised by having a beginning, middle, and end ${ }^{29-32}$. The transition seems to start long before the characteristic symptoms of COPD appear. Over time persons with
COPD begin to realise that something is not right with their health. This realisation often begins with the "crisis" phase. Subsequently, over time their health begins to deteriorate, crises become more frequent, as do trips to the emergency department. The chronic phase begins when the person with COPD experiences limitations and needs medication, oxygen therapy, and other therapeutic interventions. Even before the crisis phase and before symptoms become apparent, healthcare professionals must implement interventions intended to prevent the onset of disease, such as programmes that screen for COPD using spirometry and smoking cessation programmes. In the present study, we considered knowledge and experience were related to the outcomes of the transition process. By going through this process, a person with COPD gains the knowledge and experience needed to integrate this disease into his/ her life. This is consistent with the findings that transition processes are characterised by the development of expertise or acquisition of new skills $^{33}$. Later, those with COPD transform these skills into strategies for managing the process of becoming sick

Living with COPD is a complex and dynamic experience of learning. Some authors say that experience is a very important element for learning adult's process $^{34,35}$. Health professionals have a large contribution to make in this learning process $^{35,36}$.

Patient-advocate associations, such as RESPIRA, make it possible for many people to voice their opinions about healthcare issues, allowing them to participate actively and more formally in determining healthcare policy and social issues. Patient-advocate organisations that are interested in the same issues identify and often provide guidance and/or the means (resources and opportunities) to resolve these issues ${ }^{37}$. Essentially, they fight for the rights of special interest groups, such as persons with COPD, by trying to influence health policies not only for the benefit of individual persons but also for the benefit of all. Meanings of living with COPD are relevant. They are the social context of the findings from what had emerged as the Social Basic Process Becoming a sick person. Clarification of meanings of living can contribute to the development of self-management strategies for use during the process of becoming sick as the disease progressively worsens $s^{38}$. The inclusion of meanings in a theory of transition draws attention to the importance of understanding a transition from the perspective of those experiencing it. In this per- 
spective, the chronic illness provokes a biographical disruption ${ }^{39}$, the illness's experience meanings reflect different individual life trajectories, that happens in a sociocultural context possibilities . This disruption can't be necessarily negative but a self discovery moment, it gives an opportunity for person to show his/ her capacity to deal with illness and being well succeeded ${ }^{40}$.

In our study, person's with COPD experience looses and gains in the process of becoming sick. Meanings are very important because knowing them gives nurses useful information about how a person is living his / her experience of becoming a sick. Meanings must also be understood from the perspective of the cultural context of the transition ${ }^{18}$.

Our study is a portrait of COPD persons, some of them are empowered and are activists, and they had founded an Organization: RESPIRA. We are observing a paradigm transition in health field: patient's empowerment and participation in Health politics are a reality, relations between health and society are changing. Nurses need to change: from a information paradigm, where we use to say what to do, to an empowerment paradigm, where we "walk side by side" with person, we are facilitators, we help people managing their health /illness. In their care, nurses need to incorporate patient's illness's meanings, their practices and experience. They need to es-

\section{Collaborations}

EL Luz did the research study and participated in the conception of the article and the final writing and ML Basto participated in the conception of the article and the final writing and English revision. tablish a dialog between two worlds, the cultural model and professional one; it contributes to plan effective cultural nursing interventions.

\section{Study limitations}

Chronic populations with COPD may have different transition experience according to their culture as well as from people with advanced cancer or other diseases. Further research is needed to determine if the process identified in this study is unique to persons with COPD, in similar contexts or what varies in different cultural contexts.

\section{Conclusion}

The findings of the present study address a gap in the literature on the nature of experiencing a transition from feeling healthy to feeling sick. Meanings of living with COPD influence the process of becoming sick and we consider that participants are experts on their lives and, as such, they adopt management strategies, during the process of becoming sick, based on their experience and mastery, as well as integrate the disease and symptoms into their lives. We think that knowing the process of becoming sick from a person's perspective helps nurses to develop better interventions with COPD persons.

\section{References}

1. Odencarants S, Ehnfors M, Grobe SJ. Living with chronic obstrutive pulmonry disease: part I. Struggling with meal-related situations: experiences among persons with COPD. Scand J Caring Sci. 2005; 19(3):230-239.

2. Lomborg K, Bjorn A, Dahl R, Kirkevold M. Body care experiences by people hospitalized with severe respiratory disease. J Adv Nur 2005; 50(3):262-271.

3. Nicolson P, Anderson P. Quality of life, distress and self esteem: a focus group study of people wilth chronic bronchitis. J Health Psychol. 2003; 8(Pt 3):251-270

4. Jonsdöttir H. Life patterns of people with chronic obstruitve pulmonary disease: isolation and being closed in. Nurs Sci Q 1998; 11(4):160-166.

5. Guthrie S, Hill M, Muers M. Living with severe COPD. A qualitative exploration of the experience of patients in Leeds. Respir Medi 2001; 95(3):196-204. 
6. Heslop K. Chronic Obstrutive Pulmonary Disease from a patient perspective. Prim Care Respir J 2001; 10:75.

7. Barnett M. Chronic Obstrutive Pulmonary Disease: a phnenomenological study of patient's experiences. J Adv Nur 2004; 14:805-812.

8. RobinsonT. Living with Severe Hypoxic COPD: The patient Experience. Nurs Times 2005; 101(7):38-42.

9. Fraser D, Kee C, Minick P. Living with Chronic Obstrutive Pulmonary Disease: insider's perspectives. J Adv Nur 2006; 55(5):550-558.

10. Bailey P, Tilley S. Storytelling and interpretation of meaning in qualitative research. J Adv Nur 2002; 38(6):574-583.

11. Chen KH, Chen ML, Lee S, Cho HY, Weng LC. SelfManagement Behaviours for patient with COPD: a qualitative study. J Adv Nur 2008; 64(6):595-604.

12. Ek K, Ternestedt D. Living with chronic obstructive pulmonary disease at the end of life: a phenomenological study. J Adv Nur 2008; 62(4):470-478.

13. Theander K, Unosson M. Fatigue in patients with Chronic Obstrutive Pulmonary Disease. J Adv Nur 2004; 45(2):172-177.

14. Bailey PH. 'Dyspnea-Anxiety-Dyspnea' cycle- COPD patient's Stories of Breathlessness: "It's scary when you can't breath". Qual Health Res 2004; 14(6):760780 .

15. Bailey PH. Death stories: Acute Exacerbations of COPD. Qual Health Res 2001; 11(3):322-338.

16. Almendra M. $O$ auto controlo: Respiração na pessoa com Deficiência Ventilatória Crónica e o processo de Cuidados de Enfermagem [tese]. Lisboa: [s.n.]; 2006

17. Meleis A, Trangenstein P. Facilitating transitions: redefinition of the nursing mission. Nurs Outlook. 1994; 42(6):255-259.

18. Basto M. Da (in)visibilidade do trabalho das enfer meiras à produção de saberes em enfermagem cuidados prestados num centro de saúde: Enfermagem. Rev Portuguesa de Saúde Pública 2005; 23(1):25-41.

19. Kralik DK, Visentin A, Van Loon A. Transition: a literature review. J Adv Care 2006; 55(3):320-329.

20. Meleis A. Transitions Theory: Middle Range and Situation Specific Theories in Nursing and Practice. New York: Springer Publishing Company; 2010

21. Charmaz K. Constructing Grounded Theory: A Practical Guide Through Qualitative Analysis. London: Sage; 2006.

22. World Health Organization (WHO). Global Obstrutive Lung Disease. Washington: WHO; 2005.

23. Lubkin I, Larsen P. Chronic Illness: Impact and Interventions. Massachusetts: Jones and Bartlett Publishers; 2006.

24. Meleis A, Sawer L, Im E, Messias DHK, Schumach er R. Experiencing Transitions: An Emerging Middle Range Theory. Adv Nurs Sci. 2000; 23(1):12-28.

25. Avçar G, Kaçikçi M. Living with chronic obstructive pulmonary disease: a qualitative study. Australian J Adv Nurs 2010; 28(2):46-52.
26. Fonseca R,Vieira M. Análise crítica à Teoria Geral de Enfermagem de Dorothea Orem. Viseu: Universidade Católica Portuguesa; 2008.

27. Cicutto L, Brooks D, Henderson, K. Self Care issue from the perspective of individuals with chronic obstrutive pulmonary disease. Patient Educ Couns 2004; 55(2):168-176.

28. Bergs D. "The Hidden client": woman caring for husbands with COPD: their experience of quality of life. J Clin Nurs. 2002; 11(5):613-621.

29. Pinto J, Nations M. Cuidado e Doença Crónica: Visão do Cuidador Familiar no Nordeste Brasileiro. Cien Saude Colet 2012; 17(2):521-530.

30. Fraser C. The Experience of Transition for daughter caregiver of stroke survivior. J Neurosci Nurs. 1999; 31(1):9-16.

31. Elmberger EK, Bolund C, Lutzen R. Men with cancer: changes in attempts to Master the self-image as man as a parent. Cancer Nurs. 2002; 25(6):477-485.

32. Kralik D, Koch T, Eastwood S. The Salience of the body: transitions in sexual self identity for woman living with multiple sclerosis. J Adv Nur 2003; 42(1):11-20.

33. Van Loon A, Koch T, Kralik D. Care for female of child sexual abuse in emergency departments. Accident Emergency Nurs J 2004; 12(4):208-214.

34. Casey D, Murphy K, Cooney A, Mee L, Dowling M. Developing a Structured Education Programme for Clients with COPD. Br J Community Nurs 2011; 16(5):231-237.

35. Freire P. Pedagogia do Oprimido. Rio de Janeiro: Paz e Terra; 1970.

36. Shön D. The reflective practioner: How professional think in action. London: Temple Smith; 1983.

37. Laverack G. Promoção de Saúde: Poder e Empoderamento. Loures: Lusociência; 2008.

38. Kaptein S, Sharloo M, Fisher MJ, Snoei L, Cameron LD, Sont JK, Rabe KF, Weinmen J. Illness Perceptions and COPD: An Emerging Field for COPD Patient Management. J Asthma 2008; 45(8): 625-629.

39. Bury M. Chronic Illness as Biographical Disruption. Sociology of Health and Illness 1982; 4(16):167182.

40. Herzlich C. Saúde e Doença no Inicio do Século XXI: Entre a experiência Privada e a Esfera Pública. Physis 2004; 14(2):383-394.

Artigo apresentado em 06/06/2012

Aprovado em 14/11/2012

Versão final apresentada em 03/12/2012 